\title{
FEDERALISMO E DEMOCRACIA NO BRASIL a visão da ciência política norte-americana
}

\author{
Marta Arretche \\ Professora de Ciência Política da Unesp-Campus Araraquara. \\ Autora, dentre outros, de Estado federativo e Políticas sociais.
}

\begin{abstract}
Resumo: O artigo examina as interpretações da ciência política norte-americana sobre a natureza do federalismo brasileiro, tomando como base as orientações teórico-metodológicas da análise comparada sobre federalismo.

Palavras-chave: política brasileira; federalismo; democracia.
\end{abstract}

$66 \bigcirc$ uando o poder espanhol entrou em colapso no resto da América Latina, o mesmo aconteceu com o poder de Portugal, e o mesmo tipo de governo de caudilhos desenvolveu-se como a unidade central de poder. Esta estrutura recebeu reconhecimento formal no Ato Adicional de 1834, o qual reconstituiu o Brasil imperial sob a forma federativa. Este federalismo foi elaborado em 1889 quando a república substituiu o império. Tanto em seu início quanto em sua reconstituição, a ameaça era Portugal e a realeza brasileira, a qual era um desmembramento da realeza portuguesa. Portanto, o federalismo foi o instrumento de união dos caudilhos em face da ameaça externa e, portanto, ambas as condições da barganha estavam presentes." (Riker, 1975:119).

É isso mesmo! No Handbook of Political Science, publicado em 1975, William Riker, um dos mais influentes cientistas políticos norte-americanos e autor do capítulo sobre federalismo daquele manual, escreveu que o federalismo brasileiro teve origem com o Ato Adicional de 1834 !

Apenas para refrescar a memória histórica, lembro que, já no início dos trabalhos da Constituinte de 1823, os liberais exaltados - defensores da unidade do Império com base no princípio da adesão das províncias - foram exilados da vida política nacional, acusados por José Bonifácio, um liberal moderado, de querer promover a desunião das províncias e de que querer romper o "sagrado elo que deve unir todas as províncias deste grande Império ao seu centro natural e comum" (Faoro, 1975:12). Se é verdade que em 1834 as elites provinciais obtiveram alguma expressão política pela supressão do Conselho de Estado e do Poder Moderador, também é verdade que já no episódio da maioridade de d. Pedro II a centralização monárquica se refez: o Poder Moderador e o Conselho de Estado foram restabelecidos; o Senado era vitalício e nomeado pelo Imperador; os presidentes de província eram indicados pelo poder central assim como o juiz de paz, o chefe de polícia e os delegados e subdelegados locais.

Em suma, nada mais distante do federalismo, como definido por Riker, que a estrutura do Estado brasileiro no Império. Com efeito, segundo ele, a distinção básica entre Estado unitário, confederação e federação é que esta última supõe uma forma específica de Estado na qual o governo está verticalmente dividido entre governos regionais e governo central, de modo que cada um tem autoridade exclusiva em sua área de atuação. Ambos governam o mesmo território e a mesma população, mas cada um tem autoridade para tomar decisões independentemente do outro. Essa autoridade, por sua vez, é derivada do voto popular direto e de recursos próprios para o exercício do poder (Riker, 1964; 1975).

Como explicar, então, tamanha inadequação entre o conceito de federalismo de Riker e sua interpretação sobre o caso brasileiro? Na origem, há um problema meto- 
dológico da pesquisa comparada sobre federalismo dos anos 60 e 70, que diz respeito à referência empírica para a construção do conceito de federação. Para os autores mais influentes (Riker, 1964; Wheare, 1964; Duchacek, 1970), a versão moderna de Estado federativo foi uma invenção norte-americana e, portanto, qualquer interpretação da natureza dos Estados federativos deveria ser construída por referência às instituições políticas inventadas na Convenção da Filadélfia. ${ }^{1}$

Em Riker, o método USA-centrado não se aplica apenas ao conceito de federação, mas também à interpretação da origem das federações. Seu argumento central é que a origem de todas as federações estáveis criadas nos séculos XIX e XX foi a mesma da criação da federação norte-americana: um processo de barganha, cuja condição necessária - e suficiente, no caso dos Estados Unidos - foi a ameaça ou oportunidade de expansão ou defesa militar ou diplomática. Governos centrais com intenções expansionistas ou temerosos da ameaça externa, mas incapazes de dominar os governos locais pela força, ${ }^{2}$ cedem parte de sua autoridade aos governos locais, porque estes detêm a lealdade dos cidadãos; por sua vez, governos locais - com história e identidade próprias -, por razões expansionistas ou por necessidade de defesa, fazem concessões a uma autoridade central, para aumentar sua capacidade militar ou diplomática.

Em sua "Interpretação Militar da Constituição dos Estados Unidos" (Riker, 1964:17), o autor sustenta que a principal motivação dos Federalist Papers era a guerra e não assuntos internos ou a expansão econômica, e nem mesmo a defesa da liberdade. A barganha racional entre políticos eqüipotentes, dotados de autonomia e com a intenção de obter vantagens por meio de uma associação que supõe concessões mútuas seria, a exemplo dos Estados Unidos, a história de todas as federações contemporâneas bem-sucedidas (Riker, 1975:116).

A grande inovação da Constituição de 1787 foi a invenção do federalismo centralizado, uma fórmula associativa que criou um governo central dotado de autonomia e independência em relação aos Estados-membros. São, portanto, instituições importantes aquelas que garantem a independência do governo central, em oposição à sua dependência dos estados-membros na fórmula prévia da Confederação. A partir de 1787, a Presidência e o Legislativo centrais passaram a ser escolhidos diretamente pela população; o governo central passou a ter uma longa lista de atividades exclusivas, assim como sua autoridade prevaleceria nos casos de conflito entre os níveis de governo (Riker, 1975:109).
Mas, se o governo central concentra tantos poderes - e esta é, para Riker, a principal condição para que as federações não se desintegrem -, o que mantém as federações, isto é, que mecanismos institucionais impedem que o governo central subordine os governos locais, transformando-se num Estado unitário? Seja nos EUA, seja nas demais federações, o grau de centralização da federação seria diretamente dependente do grau de centralização do sistema partidário. Quanto maior a probabilidade de que um mesmo partido controle simultaneamente o governo central e os Estados-membros e, ainda, quanto maior a disciplina partidária dos partidos nacionais, mais fortes seriam as tendências à centralização. Alternativamente, o multipartidarismo, partidos disciplinados de base regional, a possibilidade efetiva de alternância no poder funcionariam como uma espécie de contrapeso às inevitáveis tendências centralizadoras derivadas do desenho institucional das modernas federações. ${ }^{3}$ Portanto, para Riker, é a descentralização do sistema partidário, e não o Senado, como instituição representativa dos Estados-membros, que garantiria a independência dos níveis de governo. ${ }^{4}$

Estes pressupostos teóricos tornam menos surpreendente o equívoco de Riker na interpretação do caso brasileiro. Na verdade, embora a independência entre os níveis de governo seja uma característica central das federações, sua ênfase está concentrada na dimensão centralizadora, nos mecanismos institucionais que garantem a independência e a autoridade dos governos centrais - característica esta que, com certeza, o II Império preenchia.

É certo que uma pesquisa empírica melhor fundamentada lhe permitiria observar que as condições da barganha já na Constituinte de 1823 eram, no mínimo, muito desiguais e que, no II Império, a "máquina compressora do Império" (Faoro, 1975:355) garantia a vitória eleitoral do partido que estivesse no Gabinete indicado pelo Imperador. Uma pesquisa histórica de maior profundidade lhe permitiria concluir que no II Império o Brasil não preenchia as condições essenciais de sua definição de federação (a existência de um sistema partidário descentralizado), nem as condições de emergência de uma federação (a barganha racional entre políticos eqüipotentes de diferentes níveis de governo).

Por outro lado, foi no processo de independência de Portugal que os "caudilhos" - as lideranças políticas locais que contavam com a lealdade dos cidadãos - cederam parte de sua autonomia prévia para a criação de um governo central, em face da ameaça representada por Portugal. Em 1889, quando da criação da república federati- 
va, a ameaça portuguesa não estava mais presente. Localizar, porém, a emergência do federalismo em 1889 invalidaria a tese da origem militar das federações ou, dito de outro modo, o poder explicativo e de generalização de sua interpretação centrada na trajetória norte-americana.

O mesmo método de análise empregado por Riker conduziu Wheare (1964:21) à conclusão oposta: O Brasil (de 1891) não poderia ser considerado um exemplo de federação.

Para Wheare, a grande invenção de 1787 foi a criação de um governo central, cujas atribuições e instrumentos de decisão e governo não são redutíveis à vontade dos Estados-membros, sem que, por outro lado, os estadosmembros tenham perdido a sua independência. Isto é, o governo central não pode estar subordinado aos governos regionais, nem estes subordinados ao governo central. Um Estado somente pode ser considerado federativo se as relações entre os níveis de governo forem simultaneamente de coordenação e mútua independência, princípios esses que devem estar presentes não apenas constitucionalmente, mas também no funcionamento efetivo das instituições políticas.

Assim, para Wheare, nem a União Soviética, nem a República de Weimar, nem os países latino-americanos poderiam ser considerados federações, pois, embora se auto-definissem constitucionalmente como federativos, o funcionamento efetivo de suas instituições políticas permitia que as instituições centrais subordinassem os governos regionais. No Brasil, a existência de corpos legislativos separados nos níveis central e regional, a clara divisão de atribuições entre as esferas de governo e o bicameralismo não seriam instituições políticas suficientes para garantir a efetiva independência entre os níveis de governo. O poder do Congresso para emendar a Constituição, sem ratificação dos Estados, implicaria na prática a subordinação dos governos regionais às instituições centrais, o que seria uma característica dos Estados unitários ${ }^{5}$ (Wheare, 1964:21).

Para Wheare, a garantia constitucional de que os Estados possam exercer seu poder de veto na aprovação da legislação federal é uma instituição decisiva na caracterização de uma federação. O raciocínio é claro: esta é uma característica da federação norte-americana, que garante a independência dos Estados assim como sua representação política nas instituições centrais. Dado que a referência empírica dos Estados Unidos é fundamental para distinguir formas federativas de não-federativas, Estados que não apresentarem as características essenciais do caso norte-americano não podem ser considerados federativos.
Portanto, segundo a definição de Wheare, o Brasil não seria uma federação até hoje.

Combinadas, as interpretações de Riker e Wheare sobre o Brasil nos levariam à seguinte conclusão: o Brasil já era uma federação em 1834, quando não se declarava como tal, e não é uma federação até hoje, quando declara que é! Na base desse aparente paradoxo, um problema teórico-metodológico: a referência empírica para a construção do conceito de federação e das condições de emergência e evolução dos Estados federativos.

\section{A REAÇÃO A RIKER}

Dois autores norte-americanos, pouco conhecidos no Brasil, apontaram os limites da metodologia "USA-centrada" da pesquisa comparada dos anos 60: Ivo Duchacek (1970) e Preston King (1982). Ambos consideram ser impossível afirmar que a ameaça externa ou o desejo de expansão militar estejam na origem de todas as federações. Tanto vantagens de ordem econômica, a serem obtidas pela associação de Estados, assim como o interesse em preservar a unidade nacional de um Estado (previamente) unitário, estiveram na origem das modernas federações do século XX.

A barganha federativa que deu origem ao modelo federativo de 1787 teve uma pré-condição histórica: treze Estados, cuja identidade e interesse comum se desenvolveram previamente à União e cujo propósito na Convenção da Filadélfia era preservar essa autonomia. No caso do Brasil, por exemplo, apenas algumas unidades adquiriram razoável senso de identidade previamente à formação da federação e mesmo elas tiveram que disputar seu espaço no plano federal, porque na formação da federação brasileira " a União antecedeu suas partes" (Duchacek, 1970:241). A derrota militar dos católicos pelos protestantes na União Suíça, em 1848, e a sobrevivência da própria União Americana em 1864 pela derrota militar dos Estados do sul não confirmam a tese da emergência das federações como resultado de um acordo livre e racional entre políticos eqüipotentes (King, 1982:35ss).

Mesmo o federalismo centralizado não teria sido um modelo que se generalizou. Assim como a Constituição de 1787 foi desenhada para criar um governo central dotado de mais poderes do que aqueles garantidos pelos Artigos da Confederação, a nova Constituição Federal na Alemanha de 1949 foi desenhada para criar um governo central dotado de menos poderes do que aqueles de que Hitler fez uso durante o III Reich (King, 1982:39). 
Nem mesmo a descentralização do sistema partidário poderia ser considerada uma condição necessária à manutenção das federações. Na vida real das federações, sua estabilidade estaria associada a uma diversidade de combinações que envolveriam o número de partidos efetivamente existentes, sua estrutura interna, sua ideologia, assim como o compromisso das lideranças partidárias com o pluralismo. Poderia, por exemplo, a República Velha ser chamada de federação, quando na prática havia oligarquias estaduais que não permitiam a competição partidária nas províncias, embora se revezassem no controle do governo central (Duchacek, 1970:333)?

Contudo, o grande limite dos autores que questionaram a capacidade de generalização da teoria de Riker foi sua incapacidade de construir uma teoria alternativa. Embora o reconhecimento da variedade de trajetórias tenha sido uma contribuição importante, a nova agenda da análise comparada já não deveria discutir as características essenciais do Estados federativos em relação a outras formas de Estado, pois essa contribuição já havia sido dada anteriormente. A superação da distância entre o reconhecimento da diversidade de trajetórias e a construção de uma teoria alternativa baseada no conceito de distintos modelos de federalismo implicaria a seleção de variáveis que permitissem identificar tipos específicos de Estados federativos. Essas variáveis deveriam permitir agrupar Estados cujas características fossem simultaneamente distintas externamente e semelhantes internamente. Um segundo passo para superar a distância entre a descrição dos casos e a construção de uma teoria alternativa deveria associar diferentes modelos de Estados federativos a trajetórias particulares de emergência e desenvolvimento.

Penso que uma importante contribuição nessa direção foi apresentada recentemente por Stepan (1999). Para o autor, nenhum Estado-nação criado posteriormente à Revolução Francesa com as mesmas características institucionais do federalismo norte-americano tornou-se uma federação democrática estável. A origem da federação norte-americana pela qual Estados previamente independentes "juntaram-se" para somar forças (modelo comingtogether) não se repetiu em outras federações. Portanto, ao contrário do afirmado por Riker, o caso norte-americano seria a exceção e não a regra.

Muitas das federações democráticas contemporâneas tiveram sua origem derivada da necessidade de hold together, isto é, países com múltiplas etnias em sua composição populacional e que decidiram tornar-se federações porque os Estados unitários previamente existentes estavam ameaçados de disrupção. Nestes, as unidades subnacionais não eram Estados cuja soberania prévia lhes conferia um poder de barganha, que pudesse ser comparado à trajetória dos Estados norte-americanos, o que implicou que os governos regionais tivessem menos soberania e menos poder de barganha em relação ao governo central. Em um terceiro tipo de trajetória histórica (puttingtogether), ocorreu um pesado esforço coercitivo por parte de um poder não-democrático centralizado, cujo objetivo era "juntar" um Estado baseado em diferentes etnias e nacionalidades, das quais apenas algumas estavam organizadas previamente em Estados independentes (caso da Rússia).

Assim, a origem das diferentes federações poderia ser compreendida em termos de um continuum. Em um extremo, um modelo baseado em uma barganha fortemente voluntária, pelo qual unidades relativamente autônomas come together para aumentar sua soberania, retendo suas identidades individuais (caso dos Estados Unidos, da Suíça e da Austrália). Em outro extremo, nos quais Estados unitários previamente existentes hold together, as condições de barganha dos governos locais teriam sido fundamentalmente distintas daquelas presentes no modelo comingtogether (caso da Índia, Bélgica e Espanha).

Stepan (1999) está essencialmente preocupado com a relação entre a origem das federações no século XX e suas estruturas institucionais contemporâneas, mais particularmente com as garantias institucionais de representação da vontade dos componentes da federação. Assim, embora analise o caso brasileiro do ponto de vista da segunda variável, o autor não examina as origens do federalismo no Brasil.

Embora, por exclusão, pareça atraente classificar o Brasil no modelo holding-together, uma rápida reconstituição do golpe republicano de 1889 sugere cautela na adequação desse conceito ao caso brasileiro. Não havia grupos étnicos com identidade própria reivindicando autonomia, nem ameaça real de disrupção do Estado unitário no final do século XIX. Os "cabanos" (1835), os "balaios" (1838-1840), os "sabinos" (1837) e os "farroupilhas" (1835-1845) já haviam sido violentamente controlados pelo Exército Imperial muito antes da Proclamação da República.

Na verdade, salvo melhor juízo, a literatura indica que a principal razão do golpe republicano teria sido o próprio desgaste da monarquia, processo no qual a Coroa perdeu o apoio das forças mais dinâmicas (a cafeicultura do sul e as classes médias emergentes) e dos setores mais conservadores (ligados ao escravismo, descontentes com 
a abolição) (Schwartzman, 1982). Além disso, a grita generalizada contra a centralização monárquica seria explicada pela crise fiscal do final do Império e a correlata incapacidade de atendimento das diferentes demandas regionais $^{6}$ (Costa, 1994).

Finalmente, o Estado e as instituições políticas brasileiras passaram por diversas transformações desde a origem até a versão contemporânea. Conjunturas críticas como o Estado Novo, o regime militar e a Constituição de 1988 legaram alterações importantes na natureza das relações federativas. ${ }^{7}$ Isso implica dizer que, para a interpretação dos Estados federativos contemporâneos, cuja origem seja anterior ao final do século XX, é também necessária uma teoria das condições de desenvolvimento dos distintos modelos.

\section{FEDERALISMO E PROCESSO DECISÓRIO}

Penso que, a partir de meados dos anos 80 , produziuse um deslocamento na agenda de pesquisas norte-americana sobre o federalismo: de um debate centrado nas especificidades dos Estados federativos vis-à-vis os Estados unitários e confederações, para um debate centrado no impacto do federalismo sobre a autoridade dos governos centrais, particularmente sua capacidade de mudar o status $q u o$, produzir inovações e implementar reformas de políticas.

Teoricamente, há um grau de consenso razoável em torno da seguinte proposição: Estados federativos tendem a restringir as possibilidades de mudança do status quo, porque a autonomia dos governos locais opera no sentido de dispersar o exercício da autoridade política, aumentando o poder de veto das minorias (Lijphart, 1984); ou, ainda, porque a presença de um maior número de veto players institucionalizados nas arenas decisórias aumenta o potencial de estabilidade das políticas existentes (Tsebelis, 1997). Sistemas federativos restringem o potencial de mudanças de políticas porque as garantias institucionais dos Estados-membros no processo decisório tendem a produzir decisões políticas com base no "mínimo denominador comum". (Pierson e Leibfried, 1995).

$\mathrm{Na}$ agenda de pesquisas, a análise do impacto das instituições federativas no processo decisório tende a ser uma extensão da análise das relações entre Executivo e Legislativo: "A maior parte das lições que extraímos da análise de sistemas presidenciais e parlamentares podem ser igualmente aplicada a fatores de terceiro nível (thirdtier), tais como o federalismo. Tal como os sistemas par- lamentares, federalismo é uma designação genérica que mascara uma variedade de arranjos institucionais que criam riscos e oportunidades distintas para as capacidades de governo. Governos provinciais e federais podem ter autoridade para intervir em uma área de política sem permissão do outro nível de governo. Isto tende a prover fortes incentivos para a inovação em políticas públicas na medida em que cada nível de governo tenta controlar a jurisdição de uma política antes que o outro o faça. Entretanto, este tipo de federalismo também corre o risco de que os diferentes níveis de governo tenderão a impor conflitos entre programas, elevação dos custos da implementação e tornarão o problema da coordenação de objetivos ainda mais difícil. Alternativamente, o federalismo pode ser estruturado de modo a requerer a aprovação dos governos subnacionais afetados e do governo federal para qualquer desvio do status quo. Estes arranjos (...) acrescentam pontos de veto e inibem a implementação." (Weaver e Rockman, 1993:459).

As interpretações correntes sobre o Brasil derivam dessa agenda de pesquisa. As instituições políticas brasileiras cuja natureza essencial não variou nos distintos regimes democráticos - são uma espécie de "máquina de triturar presidentes", pois a combinação de presidencialismo, sistema multipartidário, indisciplina partidária e federalismo gera um excesso de pontos de veto no processo decisório, elevando exponencialmente os custos de aprovação de reformas no Congresso. Os impasses entre o Executivo e o Legislativo, derivados dessa engenharia institucional, seriam a principal ameaça à estabilidade democrática no Brasil.

A “(...) implementação de reformas no Brasil é mais difícil do que em muitos sistemas presidencialistas. Este sistema institucional frustrou diversos presidentes democráticos. Um presidente (Vargas) cometeu suicídio; outro (Quadros) renunciou após apenas sete meses posteriormente a uma esmagadora vitória eleitoral; um outro (Goulart) adotou ações erráticas que contribuíram para o rompimento da democracia em 1964. Entre 1985 e 1994, sucessivos presidentes falharam para empreender um bem sucedido plano de estabilização, (...) a combinação de presidencialismo, sistema multipartidário fragmentado, partidos indisciplinados e robusto federalismo é freqüentemente difícil." (Mainwaring, 1997:56)

"Os últimos 15 anos de política democrática no Brasil, combinados com a experiência pluralista de 1946-64, indicam que as instituições políticas nacionais criam uma permanente crise de governabilidade, devastando em tem- 
pos normais e debilitando até mesmo presidentes como Cardoso, que parece controlar todas as cartas." (Ames, 2001:18)

"As instituições [políticas brasileiras] produzem um excesso de pontos de veto. Este excesso não é apenas uma questão do número de partidos necessários para produzir maiorias legislativas. Em termos mais amplos, o destrutivo federalismo brasileiro, que constrange a vontade da maioria, combinado com presidencialismo e com as regras eleitorais da nação, criam este excesso." (Ames, 2001:267).

Além de gerar impasses no processo decisório, a descentralização do sistema partidário e o federalismo influenciariam também o conteúdo das decisões políticas, pois os presidentes ficariam imobilizados nas áreas de política em que o Congresso e os governadores são veto players decisivos, como desindexação de salários e pensões, redução do emprego público, privatizações, política fiscal, gestão dos bancos estaduais, pagamento das dívidas estaduais, etc. (Mainwaring, 1997:99-102). Ainda: o fato de que o Brasil tenha o sistema fiscal mais descentralizado entre os sistemas presidencialistas e federativos da América Latina é explicado pelo grau de descentralização de seu sistema partidário, o qual, por sua vez, está diretamente relacionado ao poder dos políticos locais (governadores e prefeitos) sobre a sobrevivência eleitoral dos congressistas (Willis, Garman e Haggard, 1999).

Em termos muito sucintos, o argumento é o seguinte: sistemas presidencialistas, por serem baseados na divisão de poderes, tendem a produzir dispersão da capacidade decisória e coalizões parlamentares instáveis. No entanto, o sucesso legislativo da presidência pode variar de acordo com a fragmentação e disciplina partidárias. $\mathrm{O}$ número efetivo de partidos, a proximidade ideológica dos partidos de sustentação política da Presidência e o grau de disciplina dos partidos poderiam produzir resultados diferentes. Um reduzido número de partidos efetivos como nos EUA, Costa Rica e Venezuela - implica sistemas presidencialistas que funcionam melhor (Mainwaring e Shugart, 1997:398), assim como partidos políticos disciplinados e centralizados tornam mais estáveis e confiáveis as relações entre o governo, os partidos e a(s) câmara(s) legislativa(s) - como no caso do México (Mainwaring, 1997).

Entretanto, em sistemas federativos "robustos" - para usar a expressão empregada por Mainwaring (1997) para descrever o caso brasileiro -, governadores e/ou prefeitos controlam recursos que são vitais para a carreira política dos parlamentares. A descentralização dos partidos políti- cos - nos quais o comportamento parlamentar é fracamente controlado pela lideranças partidárias nacionais - é resultado do fato de que os políticos locais controlam os recursos necessários ao sucesso eleitoral dos legisladores federais, dada a extensão e persistência do clientelismo e da troca de favores na política nacional (Hagopian, 1996; Ames, 2001). Juntamente com as regras partidárias eleitorais (basicamente, a lista aberta e a representação proporcional), o poder dos governadores e prefeitos seriam as variáveis decisivas para explicar o grau de descentralização do sistema partidário e, por conseqüência, indisciplina no comportamento parlamentar dos congressistas.

Comparado com outras federações contemporâneas, o federalismo brasileiro estaria, juntamente com os EUA, no extremo da escala de demos-constraining. O sistema de composição do Senado brasileiro, semelhante ao do americano, com número equivalente de cadeiras para Estados excepcionalmente diferentes em termos populacionais, garante um excessivo grau de super-representação aos Estados menores. Os poderes legislativos do Senado brasileiro também seriam excessivos: além do poder para aprovar todas as leis e emendar a Constituição, a Câmara Alta dispõe de doze áreas de exclusividade legislativa. Em terceiro lugar, o poder residual dos Estados nos casos de omissão constitucional e o poder dos governadores, combinados ao excessivo detalhamento da Constituição de 1988 e à exigência de supermaiorias para as emendas constitucionais, impõem um extremo poder de restrição à realização das preferências da maioria. Finalmente, o controle dos governos locais sobre as candidaturas, assim como as regras eleitorais que incentivam o comportamento individualista dos parlamentares, tornam os partidos brasileiros excessivamente voláteis, isto é, pouco disciplinados. Assim, a possibilidade de transformar as preferências da maioria - expressa na escolha do Presidente - em políticas encontraria obstáculos institucionais de grande monta, pois o desenho institucional da federação alavancaria os recursos de poder das minorias nas instâncias decisórias federais, especialmente no Senado.

Não se tratará aqui de discutir a interpretação da natureza das relações entre Executivo e Legislativo no Bra$\mathrm{sil} ;{ }^{8}$ muito simplesmente, se restringirá ao conceito de federalismo dessa literatura e suas conseqüências para as interpretações sobre o Brasil. ${ }^{9}$

A nova geração de estudos sobre o federalismo contraria algumas das principais proposições da geração anterior. Para Riker (1964; 1975), a sobrevivência das federações dependia da descentralização dos partidos políticos. 
A descentralização dos partidos americanos preservaram a federação, porque criaram contrapesos à vontade do governo central. No caso dos EUA, o localismo dos partidos, derivado do fato de que as organizações locais controlam as indicações para o Congresso e a Presidência, implicam "não que os estados controlem as decisões nacionais, mas que a nação não pode controlar as decisões estaduais" (1964:91). Dada a força e independência do governo central, a descentralização do sistema partidário e a independência dos Estados funcionariam como um contrapeso às tendências centralizadoras do governo federal, preservando o federalismo (Riker, 1964:104).

Nas interpretações mais recentes, um modelo de federalismo no qual os Estados sejam independentes e tenham poder de controle sobre seus representantes nas arenas decisórias federais é um problema; no limite, uma ameaça à democracia.

Mais que isso, o México, o país latino-americano cuja centralização do processo decisório garantiria autoridade e governabilidade ao Presidente na literatura contemporânea, não era sequer considerado democrático nos estudos dos anos 60 e 70 (Wheare, 1964; Riker, 1975:156). $\mathrm{Na}$ raiz das restrições ao México, estava a centralização do sistema partidário mexicano.

Na verdade, Riker (1975:143) rejeitava o argumento de que os Estados federativos pudessem produzir algum impacto particular sobre a produção de políticas públicas. Qualquer comparação entre as respectivas políticas públicas permitiria concluir que, no campo administrativo, os Estados federativos e unitários do século XX apresentariam mais semelhança entre si do que os Estados federativos do século XX comparados consigo mesmos no século XIX. Além disso, no século XX, não haveria nenhuma característica decisiva do processo decisório dos Estados federativos que não pudesse ser encontrada nos países de Estado unitário, porque a característica central desse século foi a progressiva centralização do processo decisório.

Assim, a única diferença importante entre Estados unitários e federativos diria respeito ao estilo de governo que o governo central está obrigado a cumprir. Em Estados federativos é freqüentemente necessário ao governo central atuar de modo a demonstrar que o governo federal tem autoridade legal para fazer o que quer fazer. Mas, sem dúvida, caso o governo federal queira fazer algo, terá recursos para tal. Os "arranjos constitucionais e administrativos do federalismo afetam profundamente o estilo da decisão política, mas não afetam profundamente seus resultados" (Riker, 1975:145).
Não há dúvida de que na raiz das divergências estão questões de ordem normativa, relacionadas a preferências no tocante aos princípios de representação e governabilidade. Penso, entretanto, que há pelo menos duas distinções importantes na atual agenda de pesquisas e que têm influência nas interpretações sobre o Brasil.

Em primeiro lugar, operou-se uma restrição no escopo analítico do objeto de pesquisa: nas interpretações atuais, a análise sobre o federalismo passou a ser uma dimensão da análise das relações ente o Executivo e o Legislativo no plano federal.

Nessa agenda de pesquisas, o federalismo é entendido basicamente como a expressão do poder parlamentar de governadores e prefeitos na arena legislativa federal. $\mathrm{O}$ indicador de medida da "força" ou "fraqueza" do federalismo é a capacidade relativa de os executivos dos distintos níveis de governo influenciarem o comportamento parlamentar dos legisladores federais.

O conceito clássico de Estado federativo, como foi construído pela geração de estudos dos anos 60 e 70, o define como uma forma particular de governo dividido verticalmente (entre distintos níveis de governo), de modo que diferentes governos têm autoridade sobre a mesma população e território. Analiticamente, na literatura contemporânea, é como se a totalidade da atividade de produção de políticas públicas do executivo federal estivesse concentrada em formular uma legislação e aprová-la nas arenas decisórias federais, sejam elas o Congresso ou apenas o Senado.

Os manuais de políticas públicas nos ensinaram que o ciclo de uma política é mais do que sua formulação. Mais que isso, a literatura sobre implementação de políticas tem destacado que as burocracias governamentais de fato "fazem" as políticas públicas por meio da implementação. Isso significa que, para além da atividade de formulação, os distintos níveis de governo têm espaço para tomar uma série de iniciativas independentemente de autorização legislativa.

Além disso, os manuais de políticas públicas também nos ensinaram que a formulação de uma política é muito mais do que a obtenção de aprovação legislativa. Posteriormente à aprovação legislativa, as burocracias governamentais têm autoridade para traduzir leis em políticas efetivas, simplesmente pela definição das regras de implementação das políticas.

Isso significa que há um conjunto mais amplo de instituições políticas nas quais se opera a barganha federativa, o conflito de interesses entre executivo federal e exe- 
cutivos subnacionais. Adicionalmente, envolveriam, pelo menos, as relações com o Judiciário e as relações diretas entre os executivos dos distintos níveis de governo. Reduzir a análise do funcionamento das instituições federativas à arena legislativa federal implica necessariamente uma visão parcial e limitada dos recursos de poder de que dispõem os distintos níveis de governo para fazer representar seus interesses.

Em segundo lugar, as interpretações contemporâneas têm enfatizado e selecionado para análise as políticas e decisões de política nas quais o governo federal teve um desempenho desfavorável. Para demonstrar a progressiva centralização das funções administrativas nos Estados Unidos, Riker (1964:191ss) selecionou 19 áreas de competências concorrentes entre os níveis de governo, o que lhe permitiu ter uma visão abrangente da evolução das relações intergovernamentais.

A preferência pelos casos nos quais o governo federal encontrou resistência pode estar produzindo um bias pela variável dependente nas interpretações sobre o federalismo brasileiro, uma vez que o processo decisório das políticas nas quais o governo federal foi bem-sucedido na implementação de sua agenda de reformas de natureza federativa não é objeto da análise. Nessa situação, mais uma vez, o que é apenas uma dimensão das relações federativas é tomado como $a$ natureza do federalismo brasileiro.

\section{COMENTÁRIO FINAL}

Esta revisão crítica pretendeu demonstrar que, embora a federação brasileira tenha sido objeto de pesquisa nas análises da ciência política comparada norte-americana, ainda há muito a ser feito neste campo de investigação.

Estudos comparados são particularmente árduos, dadas as dificuldades de toda ordem, particularmente a obtenção de dados confiáveis e comparáveis entre si. Este artigo, contudo, pretendeu destacar avanços e dificuldades passadas e presentes no campo teórico-metodológico. É certo que, no passado recente, indicações bastante sugestivas de análise têm sido feitas, especialmente no sentido de superar a perspectiva USA-centrada que orientava a teoria comparada sobre federalismo nos anos 60 e 70 .

Penso, entretanto, que a análise comparada das federações ainda necessita de uma teoria capaz de sugerir caminhos interpretativos sobre a origem dos diferentes modelos das federações contemporâneas, mas também dos condicionantes históricos de suas diferentes trajetórias.
Quanto às análises contemporâneas, pertinentes às relações entre federalismo, democracia e processo decisório, o principal objetivo deste artigo foi destacar a necessidade de uma ampliação da agenda de pesquisas sobre a natureza das relações intergovernamentais no Brasil. Penso que as interpretações atuais tendem a reduzir o escopo da análise, concentrando-se excessivamente nos casos em que o governo federal teve um desempenho relativamente desfavorável vis-à-vis os governos estaduais, assim como em uma das arenas nas quais se processam as relações intergovernamentais: a arena legislativa federal. Uma ampliação dessa agenda de pesquisas deveria caminhar basicamente em duas direções: no exame de processos decisórios nos quais o governo federal foi bem-sucedido em implementar sua agenda de reformas, assim como na análise do processo decisório de políticas que envolvam relações diretas entre o Poder Executivo dos distintos níveis de governo e/ou nas quais o Poder Judiciário funcione como árbitro dos conflitos intergovernamentais.

\section{NOTAS}

E-mail da autora: arretche@uol.com.br

Este artigo foi escrito com base em pesquisa realizada durante meu programa de pós-doutoramento junto ao Department of Political Science do Massachussets Institute of Technology, MIT, financiado com bolsa concedida pela Fapesp. Agradeço a Celina Souza pelos valiosos comentários à primeira versão (do texto).

1. Modernos, neste caso, seriam os Estados federativos baseados no princípio da "república 'composta" " proposta por Madison, em oposição ao modelo confederativo anterior (como nos Estados Unidos de 1777 e nos modelos federativos originais da Suíça e Holanda), baseados na concepção federativa de Montesquieu.

2. A decisão da barganha derivaria dos elevados custos de obtenção da adesão pela força (Riker, 1964).

3. "A essência do federalismo nesta definição são suas características políticas: (1) a barganha política que o cria e (2) a distribuição de poder em partidos políticos que dão forma à estrutura federativa em sua maturidade. Todo o resto sobre o federalismo é acidental: a demarcação de áreas de competência entre governo central e governos constituintes, a operação das relações intergovernamentais, a divisão de recursos fiscais etc.” (Riker, 1975:141).

4. Riker (1975) considera que, na Convenção da Filadélfia, o Senado foi concebido como a instituição destinada a representar os interesses dos Estados-membros no governo central. Na prática, contudo, a Câmara Alta nunca representou de fato esse papel, pois os Estados-membros foram rapidamente desprovidos de mecanismos institucionais para controlar o comportamento parlamentar de seus representantes, uma vez que não tinham poder para revogar seus mandatos.

5. Nos Estados Unidos, emendas à Constituição, mesmo que não afetem a distribuição federal de poderes, exigem a ratificação de $3 / 4$ dos Estados-membros e há mesmo tipos de emendas que não podem ser aprovadas sem a ratificação de 49 dos 50 Estados (Duchacek, 1970:231).

Para um exemplo, ver Mansbridge (1986), que analisa as razões pelas quais o Equal Rights Movement - ERA - fracassou em aprovar a Emen- 
da Constitucional que garantiria direitos iguais a homens e mulheres. Embora tenha sido aprovado no Senado dos Estados Unidos com uma votação de 84 contra 9 , e embora diversas pesquisas de opinião tenham revelado forte apoio da opinião pública à Emenda Constitucional, esta não foi aprovada porque as casas legislativas estaduais aprovaram a Emenda em apenas 35 Estados, quando seria necessário que 38 Estados o tivessem feito.

6. Esta tem um fundamento real: quando examinada a relação entre as receitas geradas em cada província e as despesas ali efetuadas pelo governo central, constata-se que todas as províncias - com exceção do Rio Grande do Sul e Mato Grosso, por razões militares - transferiam recursos para a Coroa (Costa, 1994:27).

7. Para interpretações sobre a evolução do federalismo brasileiro, ver Souza (1994) e Souza (forthcoming).

8. Para uma interpretação alternativa sobre a natureza das relações entre Executivo e Legislativo no Brasil nos governos democráticos recentes, ver Figueiredo e Limongi, 1999. Para uma reconstituição deste debate, ver Palermo, 2000.

9. Para diferentes interpretações sobre a natureza do federalismo brasileiro, com base no conceito da força relativa do executivo federal e dos executivos estaduais, ver Abrucio (1998) e Souza (forthcoming).

\section{REFERÊNCIAS BIBLIOGRÁFICAS}

ABRUCIO, F.L. Os barões da Federação. São Paulo, USP/Hucitec, 1998.

AMES, B. "Electoral Rules, Constituency Pressures, and Pork Barrel: Bases of Voting in the Brazilian Congress". The Journal of Politics, v.57, maio 1995 , p.324-43.

. The Deadlock of Democracy in Brazil. University of Michigan Press, 2001.

ARRETCHE, M. Estado Federativo e Políticas Sociais. Rio de Janeiro, Revan, 2000.

COSTA, W.P. "A questão fiscal na crise do império e na implantação da república". Relatório de Pesquisa. Projeto: Balanço e perspectivas do federalismo fiscal no Brasil. São Paulo, IESP/Fundap, 1994, mimeo.

DUCHACEK, I.D. Comparative Federalism. The Territorial Dimension of Politics. Santa Barbara, Holt, Rinehart and Winston Inc., 1970.

FAORO, R. Os donos do poder. Porto Alegre/São Paulo, Globo/USP, 1975.

FIGUEIREDO, A. e LIMONGI, F. Executivo e Legislativo na nova ordem constitucional. Rio de Janeiro/São Paulo, FGV/Anpocs, 1999.

GREENSTEIN, F.I. e POLSBY, N. (ed.). Handbook of Political Science. Massachusetts, Addison-Wesley Publishing Company, v.5, 1975 .

HAGOPIAN, F. Traditional Politics and Regime Change in Brazil. Cambridge, Cambridge University Press, 1996.

KING, Preston. Federalism and Federation. Baltimore: John Hopkins University Press, 1982.

LIJPHART, A. Democracies. Patterns of Majoritarian and Consensus Government in Twenty-One Countries. New Haven, Yale University Press, 1984.
. Patterns of Democracy: Government Forms and Performance in Thirty-Six Countries. New Haven, Yale University Press, 1999.

MAINWARING, S. "Multipartism, Robust Federalism, and Presidentialism in Brazil". In: MAINWARING, S. e SHUGGART, M. Op. cit., 1997.

MAINWARING, S. e SAMUELS, D. "Federalism, Constraints on the Central Government, and Economic Reform in Democratic Brazil". In: GIBSON, E. Representing Regions: Federalism and Territorial Politics in Latin America (forthcoming).

MAINWARING, S. e SHUGGART, M. Presidentialism and Democracy in Latin America. Cambridge, Cambridge University Press, 1997.

MANSBRIDGE, J.J. Why we lost the Era? Chicago/London, University of Chicago Press, 1986.

PALERMO, V. "Como se governa o Brasil? O debate sobre instituições políticas e gestão de governo”. Dados, v.43, n.3, 2000, p.52157.

PIERSON, P. e LEIBFRIED, S. European Social Policy. Between Fragmentation and Integration. Washington, Brookings Institution, 1995.

RIKER, W. Federalism, Origin, Operation, Significance. Little, Brown and Company, 1964.

"Federalism". In: GREENSTEIN, F. and POLSBY, N. (ed.). Handbook of Political Science. Massachusetts, AddisonWesley Publishing Company, v.5, 1975.

SAMUELS, D. "Concurrent Elections, Discordant Results. Presidentialism, Federalism, and Governance in Brazil". Comparative Politics, v.33, n.1, out. 2000, p.1-20.

SCHWARTZMAN, S. Bases do autoritarismo brasileiro. Brasília, Universidade de Brasília, 1982.

SOUZA, C. "Brazil: The Prospects of a Center-Constraining Federation In: "A Fragmented Polity". Publius (forthcoming).

SOUZA, M. do C.C. de. "Aspectos político-institucionais do federalismo (1930-1964). Relatório de Pesquisa. Projeto: Balanço e perspectivas do federalismo fiscal no Brasil". São Paulo, IESP/Fundap, 1994, mimeo.

STEPAN, A. "Para uma nova análise comparativa do federalismo e da democracia: federações que restringem ou ampliam o poder da demos". Dados, v.42, n.2, 1999, p.197-251.

TOCQUEVILle, A. de. A democracia na América. Belo Horizonte/ São Paulo; Itatiaia/USP, 1977.

TSEBELIS, G. "Processo decisório em sistemas políticos: veto players no presidencialismo, parlamentarismo, multicameralismo e pluripartidarismo. Revista Brasileira de Ciências Sociais, v.12, n.34, jun. 1997, p.89-117.

URICOECHEA, F. “O Estado brasileiro moderno: das máximas patrimoniais aos princípios burocráticos”. Dados, n.15, 1977, p.6182.

WEAVER, K.R. e ROCKMAN, B. Do Institutions Matter? Washington, Brookings Institution, 1993.

WHEARE, K.C. Federal Government. Nova York: Oxford University Press, 1964.

WILLIS, E.; GARMAN, C. da C.B; HAGGARD, S. "The politics of decentralization in Latin America". Latin American Research Review, v.34, n.1, 1999, p.7-56. 